\title{
IoT Tabanlı ve Makine Öğrenmesine Dayalı Seçici Sulama Sistemi
}

\author{
Harun Dolcel $^{1 *}$, Mahmut Durgun ${ }^{2}$, Levent Gökrem³ \\ $\mathbf{1}^{*}$ Tokat Gaziosmanpaşa Üniversitesi, Tokat, Türkiye (ORCID: 0000-0001-9046-1377), harundolcel@gmail.com \\ 2 Tokat Gaziosmanpaşa Üniversitesi, Tokat, Türkiye (ORCID: 0000-0002-5010-687X), mahmut.durgun@gop.edu.tr \\ 2 Tokat Gaziosmanpaşa Üniversitesi, Tokat, Türkiye (ORCID: 0000-0003-2101-5378), levent.gokrem@gop.edu.tr
}

(1st International Conference on Applied Engineering and Natural Sciences ICAENS 2021, November 1-3, 2021)

(DOI: 10.31590/ejosat.1002401)

\begin{abstract}
ATIF/REFERENCE: Dolcel, H., Durgun, M. \& Gökrem, L. (2021). IoT Tabanlı ve Makine Öğrenmesine Dayalı Seçici Sulama Sistemi. European Journal of Science and Technology, (28), 395-401.

\section{$\ddot{O} \mathbf{z}$}

Nüfus artışı, kentleşme ve iklim değişikliği nedeniyle, özellikle tarım üzerinde olmak üzere su kaynakları için rekabetin artması beklenmektedir. Ülkemizde kişi başına düşen yıllık kullanılabilir su miktarı $1.500 \mathrm{~m}^{3}$ civarında olduğu için su sıkıntısı bulunan ülke konumundayız. Bu yüzden var olan kısıtlı, kullanılabilir su kaynaklarının kullanılması konusunda tasarrufa gidip, kullanım konusunda dikkatli davranıp, özen göstermeliyiz. Planlanan bu çalı̧̧ma çeşitli ürünlerin yetiştirildiği bahçelerde, toprağa ekilen ürünlerin çeşitliliğine uygun olarak her bir ürün için özel bir sulama reformu oluşturmak, su kaynaklarının etkin ve doğru kullanımıyla birlikte üretim verimliliğini artırmak için tarım tesislerindeki yeni yapı entegre veri toplama sistemi ve makine öğrenmesi sistemini sunmaktadır. 8 farklı ürün için nesnelerin interneti tabanlı, uzaktan kontrollü ve yapay zekâya dayalı çok katmanlı sistemin tasarımını ve geliştirilmesini sunmaktadır. Çok katmanlı sistem, kırsal ortamlarda bilgi keşfi ve karar verme için kablosuz sensör ağlarından gelen bilgileri yönetir. Önerilen çok katmanlı sistem, kırsal bir ortamda gerçekleştirilen faaliyetlerde karar vermek için sensörler tarafindan toplanan verileri analiz etmemize olanak tanıyarak ürünlerin sulanmasında en az su kullanımı ile en iyi verimi almayı hedeflemektedir. $\mathrm{Su}$, israf edilmemesi gereken kıt bir doğal kaynak olduğundan, önerilen sistemle ürün çeşidine göre sulama yapılması, canlı veri takibinin yapılması ve tüm bu verilere herhangi bir yerden mobil cihazlar veya bilgisayar üzerinden takibi ve kontrolü amaçlanmaktadır. Çalışmada yer alan cihazların her türlü arazi ortamında çalıştırılması düşünülmüsşür. Bu kapsamada proje kullanılacak olan tüm enerji ihtiyacı yenilenebilir enerji kaynakları (Güneş Fotovoltaik) üzerinden sağlanmaktadır.
\end{abstract}

Anahtar Kelimeler: Seçici Sulama, Makine Öğrenmesi, Uzaktan İzleme, Fotovoltaik Enerji.

\section{Selective Irrigation System Based On IoT And Machine Learning}

\begin{abstract}
Due to population growth, urbanization and climate change, competition for water resources, especially over agriculture, is expected to increase. Since the annual amount of usable water per capita in our country is around 1,500 $\mathrm{m} 3$, we are in the position of a country with water shortage. That's why we have to save money on the use of limited, usable water resources and be careful about using them. This planned study presents a new structure integrated data collection system and machine learning system in agricultural facilities in order to create a special irrigation reform for each product in accordance with the variety of products planted in the soil, in the gardens where various crops are grown, and to increase production efficiency with the effective and correct use of water resources. In the study, it presents the design and development of an internet-based, remote-controlled and artificial intelligence-based multi-layer system for 8 different products. The multi-layer system manages information from wireless sensor networks for information discovery and decision making in rural environments. The proposed multi-layer system allows us to analyze the data collected by the sensors to make decisions in activities carried out in a rural environment, aiming to get the best efficiency with the least water use in irrigating the crops. Since water is a scarce natural resource that should not be wasted, the proposed system aims to irrigate according to the type of product, to monitor live data, and to monitor and control all these data from anywhere via mobile devices or computers. The devices in the system are intended to be operated in all kinds of terrain. In this context, all energy needs to be used in the project will be realized through renewable energy sources (Solar Photovoltaic).
\end{abstract}

Keywords: Selective Irrigation, Machine Learning, Remote Monitoring, Photovoltaic Energy.

\footnotetext{
* Corresponding Author: hdolcel@gmail.com
} 


\section{Giriş}

Dünyadaki nüfus artışı, şehirleşme ve iklim değişikliği, içilebilir su ve özellikle tarım üzerinde olmak üzere su kaynakları için rekabetin artması beklenmektedir. Dünya nüfusunun 2050 yılına kadar 10 milyarı aşması bekleniyor ve ister şehir yaşamında ister kırsal yaşam olsun, bu nüfusun yaşamını sürdürebilmesi için temel gıda ihtiyacı olacaktır. Her geçen gün artan dünya nüfusunun $r$ artışına eşlik eden yüksek kalorili yiyecekler ve hazır g1da tüketiminin neticesinde tarım ürünlerine olan talebin 2050 yılına kadar yaklaşık \%70 oranında artması gerektiği tahmin edilmektedir.(Baştuğ 2014)

Bununla birlikte, gelecekte suya olan talebin artmas1, özellikle su sıkıntısı çeken bölgelerde tarımsal faaliyetlerle birlikte suyun $\% 25$ ile \%40' ının düşük verimliklikte kullanımlası sonucu tarladan çıkan ürünlerde azalma meydana getirecektir.(Kalkınma bakanlığı, 2018) Özellikle tarımsal sulama da suyun bilinçsiz kullanımı tarım arazilerinde verim kaybına neden oalcaktır. . Şu anda tarım arazilerinde kullanıma sulama suyu, küresel olarak çekilen tüm tatlı suların \%70'inden fazlasını kapsamaktadır.(Tatl \& Amerika, 2000)

Yanlış sulama uygulamaları özellikle tarıma dayalı ekonomiye sahip ülkelerin, tarımsal ürünlerde de dışa bağımlı hale gelmelerinin sağlayacaktır. $\mathrm{Bu}$ durum ülke için gida fiyatlarının kura bağlı olarak artmasını, beraberinde enflasyonu ve toplumsal yoksullaşmayı doğuracaktır. Bu bağlamda, tarımsal üretimde, yüksek teknolojili içerikli akıllı tarım uygulamaları, tarımsal gelire sahip ülkelerdeki büyüme için yeni stratejik bir role sahip olmaya başlamıştır.(Kılavuz \& Erdem, 2019)

Türkiye'de şu an 112 milyar $\mathrm{m}^{3}$ kullanılabilir su kaynağının bulunmaktadır. Bu sudan yararlanma oranı yaklaşık \%39 olup, 32 milyar $\mathrm{m}^{3}$ 'ü tarımsal sulama, 7 milyar $\mathrm{m}^{3}$ 'ü hane halkının içme ve diğer kullanımları, 5 milyar $\mathrm{m}^{3}$ ' $\ddot{\mathrm{u}}$ ise sanayi tesisleri için kullanılmaktadır. Türkiye'deki su kaynakalrının kullanıma bakıldığında, su kaynaklarının yaklaşık \%73'ü tarımsal sulama, \%11'i endüstri, \%16'sı evsel tüketim için kullanılmaktadır. Su kullanım durumu Dünyada \%70 tarımsal sulama, \%22 endüstri ve $\% 8$ kentsel kullanımdadır, Avrupa'da ise \%33 tarımsal sulama, $\% 51$ endüstri ve \%16'sı kentsel kullanım içindir. (Özel İhtisas Komisyonu Raporu, 2018)

Ülkemizin 2019-2023 y1lı kalkınma planında yer alan “416.4. Akıllı tarım teknolojileri başta olmak üzere yenilikçi ve çevreci üretim teknikleri geliştirilecek ve desteklenecektir".ifadesiyle tarım alanında yapılacak olan akıllı teknolojilerin geliştirilmesi ve desteklenmesi hedeflenmektedir.(Kalkınma bakanlığı, 2018)

Bilinçsiz sulama su kaynaklarının azalmasına neden olurken bitkilerinde elde edilecek olan verimin düşmesine sebep olmaktadır. Bitkilerin özellikle büyüme süresi boyunca bitki kök bölgesinde yeterli düzeyde nemin bulunması bitki gelişimi açısından çok önemlidir. Bitkinin ihtiyacından az ya da çok olan toprak nemi verimliliği etkilemektedir.(Dorak et al., 2019)

Çalışmanın temel odak noktası, tarım alanlarında ki su kaynaklarının verimli kullanılması ve yetiştirilen ürünlerden azami düzeyde verimlilik sağlayacak akıllı ve bitkiye özgü seçici sulama sistemi oluşturmak.

Çalışmada çevresel veriler sensörler aracılığı ile elde edilecektir. Bu veriler tam olarak netlik kazanmasa da çalışmamız için planlanan ve sensörler ile ölçülecek olan fiziksel büyüklüklüler; toprak nem miktarı, hava sıcaklığı, hava nem miktarı. Ayrıca kullanıcı aracılığı ile girilecek veriler; bitkinin türü ve bitkinin gelişim evresi. Oluşturulacak kablosuz ağ topolojisi ile tüm birimleri birbirine bağlama, buna bağlı olarak kablolama seviyesini azami düzeye indirilecektir. Ayrıca birçok merkezi birim oluşturulması ve bu birimleri hem sensörler hem de kendi aralarında haberleşmesi, sensörlerde gelen bilgi, mevcut hava durumu, sulanacak olan bitkiye özel sulama rejiminin oluşturulması ve tüm bu unsurları uzaktan takip edilmesi planlanmaktadır. Oluşturulacak olan tüm sistem makine öğrenmesi üzerine inşa edilecektir. Ortamdan elde edile tüm veriler ve kullanıcılar aracılığ 1 ile girilecek olan verilerden bir veri seti oluşturulacaktır. Veri seti, makine öğrenmesi ve kullanılacak algoritmalar ile bitkiye özgü seçici sulama rejiminin oluşturulması sağlanacaktır.

\section{Materyal ve Metot}

\subsection{Metot}

Çalışmada en önemli kısımlarında biri olan verilerin toplanması ve bitkiye özgü veri setlerinin oluşturulmasıdır. Verilerin toplanması kablosuzu sensörler aracılığı ile gerçekleştirilecektir. Kablosuz sensör topolojisi, birbirinden farklı sensörler aracılığıyla çevreleri ile etkileşime girebilme, bilgi işleyebilme ve elde edilen verileri kablosuz olarak çevresindeki bağlantı (düğüm) veya internet ortamlarına aktarabilme özelliklerine sahiptir. Bu çalışmada tasarlanan yapı birçok sensörü içinde barındırmaktadır. Sensörler bulundukları ortamlardaki bilgiyi işleyebilen ve topladığı verileri kablosuz olarak sensör düğümüne ve sensör düğümünden gelen verileri bilgisayar ortamında saklayabilen bir sistem üzerine inşa edilecektir. Çalışma da yer alan ve veri toplamak için kullanılacak çeşitli sensörler vardır. Sistemde bir bahçe / tarla üzerinden 8 farklı bitkinin, sensörlerden gelen bilgiye ve bitkinin cinsi ve büyüme (tohum, fide, çiçeklenme vb.) durum verilerini elde edilmesi ve bu verilere dayanarak makine öğrenmesi yoluyla her bir bitkinin kendine has bir şeklide sulanması sağlanmaktadır. Sistemde enerji kaynağı yenilenebilir kaynaklardan sağlanmaktadır. (Şekil-1). Sistemin ana kontrol merkezi Wi-Fi özelliğine sahip ve kablosuz iletişim kurabilmektedir. (Şekil-2 ve Şekil-3). Sistem tasarımının yapay zekâ / makine öğrenmesi deneyleri laboratuvar ortaminda test edilmektedir. Sistemde su miktarları selenoid valfler aracılığı ile kontrol edilmektedir. Sisteme elde edilene veriler neticesinde bir veri oluşturulup makine öğrenmesi için temel oluşturulmaktadır. (Şekil-4). Bu sayede bitkiye özgü olarak sulama miktarları belirlenmektedir. Aşağıda tasarımda kullanılan belli başlı önemli devre elemanları, sensörler, elektronik sistemler ve yapay zekânın temeli hakkında bilgilere de yer verilmiştir. Sistem ve makine üzerine çalışmaların devam ediyor olması sebebiyle kesinleşen veriler bu makalede paylaşılmamıştır. 


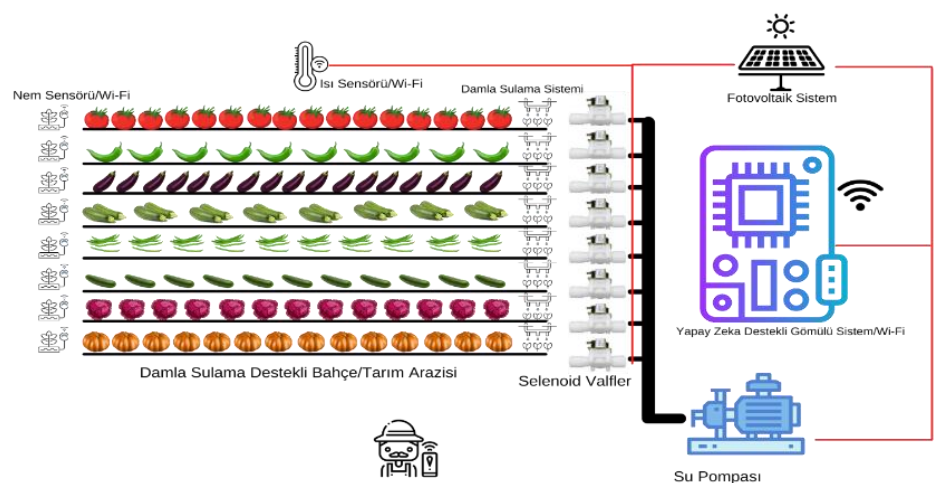

Şekil 1. Sistemin Genel Şeması

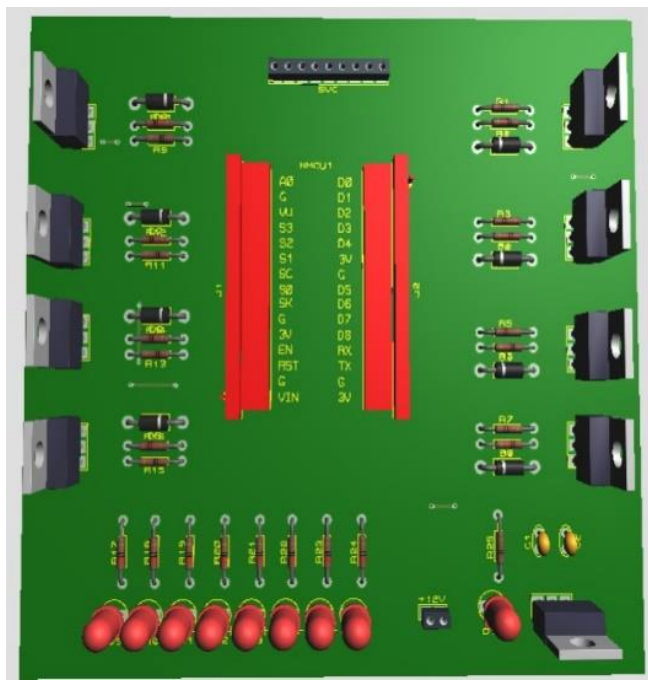

Şekil 2. Yapay Zekâ Destekli Gömülü Sisteme Devre Tasarımı (Üst Görünüm) - Wi-Fi

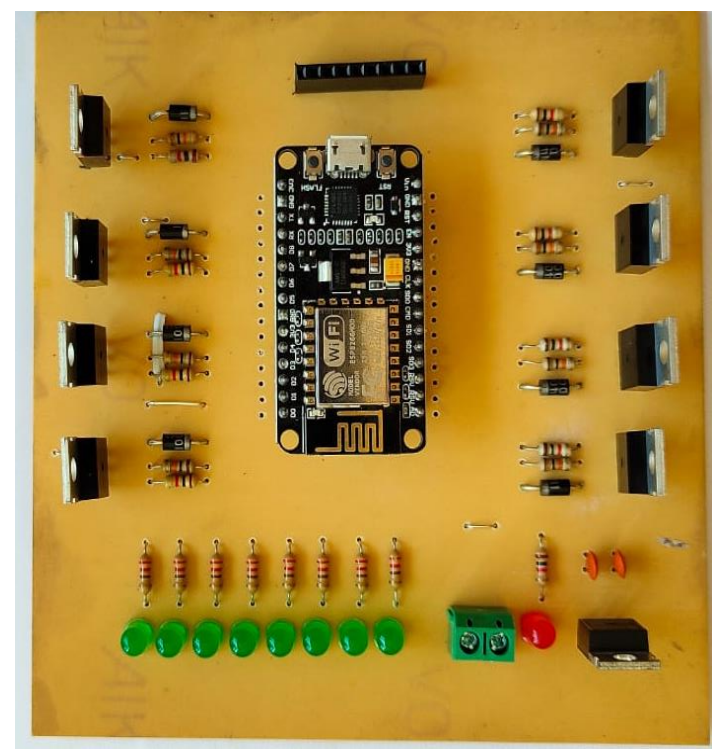

Şekil 3. Yapay Zekâ Destekli Gömülü Sisteme Devre Uygulaması (Üst Görünüm) - Wi-Fi

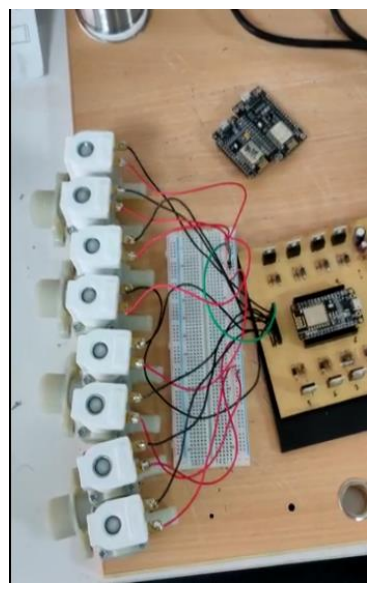

Şekil 4. Gömülü Sistem ve Selenoid Valflerin Test Edilmesi

\subsubsection{Sıcaklık ve Nem Sensörü}

Hava sıcaklığı ve neminin ölçmek için kullanılan 0.1 hassaiyet ölçülerine sahip sensördür. Uzun süreli velışma yüksek kararlık özelliklerine sahpitir. 8 bitlik mikroişlemci mimarisine sahiptir. Sıcaklık ölçüm aralığı $0^{\circ} \mathrm{C}-50^{\circ} \mathrm{C}$ aralığında $2^{\circ} \mathrm{C}$ hata payına sahiptir. Nem ölçümü aralığı \%20-\%90 RH arasında ve $\% 5$ 'lik RH hata payına sahiptir.(DHT11 Sicaklık ve Nem Sensörü, 2021)

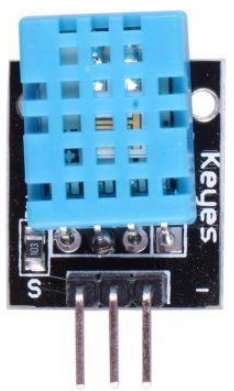

Şekil 5. Sicaklık Ve Nem Sensörü

\subsubsection{Kapasitif Toprak Nem Sensörü}

Kapasitif toprak nem sensörü, diğer nem sensörlerinden farklı olarak direnç değeri algılamak yerine Kapasitif algılama ile topraktaki nem miktarını ölçebilmektedir.

Çalışma gerilimi: DC 3.3-5.5V Çıkış voltajı: DC 0-3.0V Arayüz: PH2.0-3P (Kapasitif Toprak Nem Sensörü Higrometre, 2021)

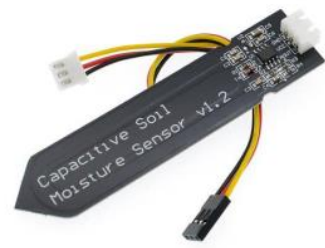

Şekil 6. Kapasitif Toprak Nem Sensörü 


\subsubsection{Mikro Kontrol Ünitesi}

NodeMCU; WiFi özelliğiyle kolay iletişim özelliğine sahiptir. Programlanabilir ve ucuz maliyeti ile özellikle IoT projelerinde siklikla tercih edilmektedir. Dijital I/O, Analog I/O, PWM çıkışları ve Wi-Fi ile kablosuz haberleşmeye imkan tanımaktadır. NodeMCU Wi-Fi kontrol ünitesine ait pin yapısı Şekil 7'de görülmektedir.(Taştan, 2019)

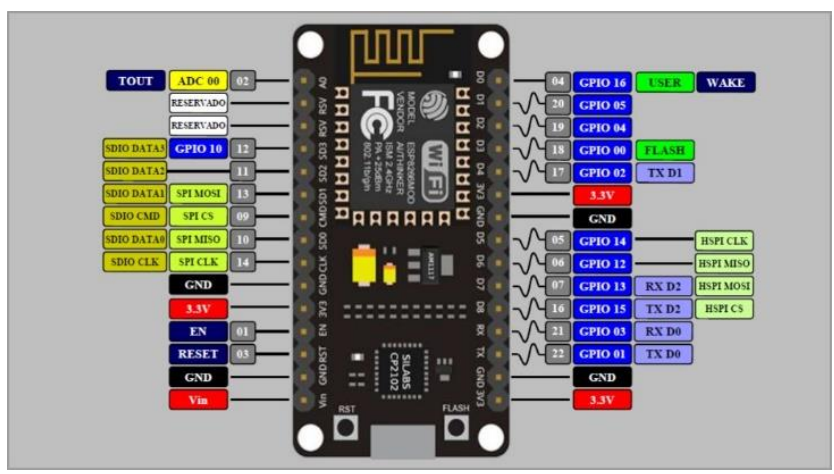

Şekil 7. NodemCU V3

NodeMCU gömülü Wi-Fi modüle sahip özel bir IoT denetleyicisidir. 32 bitlik 160 MHz' de çalışan LX106 mikro denetleyicisi içerir. NodeMCU' yu programlayabilmek için $\mathrm{C}$ ve $\mathrm{C}++$ temelli yazılım dilleri kullanılacaktır. Tablo 1 'de ise NodeMCU kontrol modülüne ait teknik veriler görülmektedir.(Taştan, 2019)

Tablo 1. NodeMCU' nun teknik verileri (NodeMcu -- An Open-Source Firmware Based on ESP8266 Wifi-Soc.,2021)

\begin{tabular}{|l|l|}
\hline Özellikler & Dĕ̆ger \\
\hline MCU & 32 bit Tensilica L106 \\
& İşlemci Frekansı \\
& $80 / 160 \mathrm{MHz}$ \\
\hline Input/Output & $13 \times \mathrm{DIO}$ \\
\hline ADC Pin & $1 \times 10 \mathrm{bit}(1 \mathrm{~V})$ \\
\hline Çalışma Gerilimi & $3.0 / 3.6 \mathrm{~V}$ \\
\hline Çalışma Akımı & $12-200 \mathrm{~mA}$ \\
\hline Program Hafızası & $4 \mathrm{MB}$ \\
\hline WiFi & IEEE $802.11 \mathrm{~b} / \mathrm{g} / \mathrm{n}$ \\
\hline Sleep Mode Akım & $<10 \mathrm{uA}$ \\
\hline Standby Mode Akım & $<10 \mathrm{~mA}$ \\
\hline
\end{tabular}

\subsubsection{Fotovoltaik Sistem}

Üzerine gelen güneş 1şınlarını düşük seviyede elektrik enerjisine dönüştüren aygıtlara güneş pili denir. Daha yüksek gerilim ve akım elde etmek için çok sayıda güneş pilleri seri ve paralel bağlanarak elde edilen aygıta güneş paneli denir. (Topuz et al., 2017) (Şekil-8)

Çalışmamızda yapılan hesaplamalar doğrultusunda $40 \mathrm{~W}$ güce sahip Fotovoltaik panel(ler) ve 2x 12V 7A'lik doğru akım aküleri ile sistemin enerji ihtiyacı karşılanabileceği düşünülmektedir.

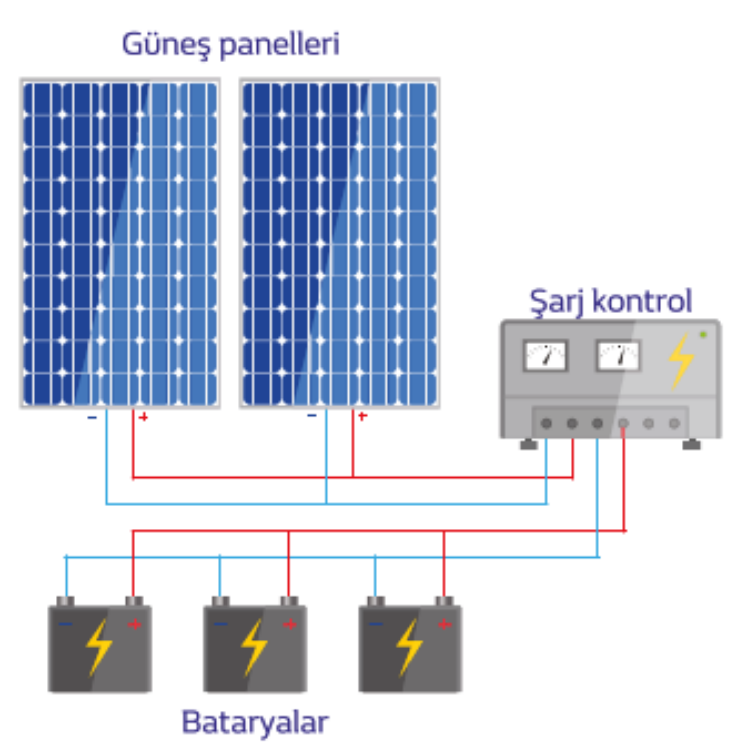

Şekil 8. Güneş Enerji Sistemi (Fotovoltaik)

\subsubsection{Selenoid Valf}

Selenoid Valf; su, hava, yağ vb. gaz ve sıvıları kontrol etmek için kullanılan elektromanyetik vanalardır. Selenoid valfin içeresinde bir bobin sargısı mevcuttur. Bu sargıya elektrik akımı uygulandığında bobin elektromıknatıs özelliği gösterir. Valfin içerisinde bulunan metal piston elektromıknatısın etkisi ile konum değiştirir. $\mathrm{Bu}$ tarz valfler iki konumludur. Normalde Açık Kontaklı Valfler; normalde sıvı akışına müsaade etmez ancak bobine elektrik akımı uygulandığında valf konum değiştirir ve sıvının geçişine izin verir. Normalde Kapalı Kontak Valfler; normalde sıvının akışına izin veriler ancak bobine elektriksel güç uygulandığında valf konum değiştirir ve sıvı akışını durdurur. Sistemde $12 \mathrm{~V}$ DC gerilimde çalışan selenoid valfler kullanılmıştır. (Genel Kullanım Selenoid Valf,2021)

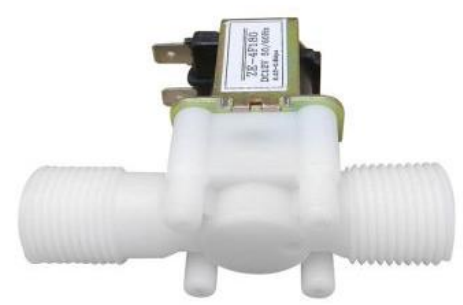

Şekil 9. Selenoid Valf

\subsubsection{Makine Öğrenmesi}

Verilerin elde edilmesi ve veri setlerine dönüştürülmesinin temel amacı makine öğrenmesi için zemin hazırlanması sağlamaktır. Çünkü makine öğrenmesinde en önemli unsur veridir. Çalışmamızda sensörler ile elde edilen veriler, veri setlerine dönüștürülecek makinenin karar vermesi için birer veri tabanı görevi göreceklerdir.(Jha et al., 2019)

Makine öğrenmesi, belirlenen problemi, probleme özgü elde edilen verilere göre yorumlayan ve karar veren algoritma yöntemlerinin genel adıdır. Probleme ait verileri göre oluşturulan algoritmalar, en yüksek performansı vermek üzere 
kurgulanmaktadır. Bu nedenle makine öğrenmesi için birçok algoritma yöntemi geliştirilmiş olup bunlardan bazıları;

- K-en yakın komşu algoritması,

- Basit (naive) Bayes sinıflandırıcı,

- Karar ağaçları,

- Lojistik regresyon analizi,

- K-ortalamalar algoritması,

- Destek vektör makinaları

- Yapay sinir ağları,

- Bu yöntemlerde öğrenme stratejileri;

- Denetimli öğrenme,

- Denetimsiz öğrenme

- Pekiştirmeli (takviyeli) öğrenmedir.

Genel olarak makine öğrenmesi 3 temel yapı üzerinde incelenmektedir.

Bunlar;

- Denetimli öğrenme,

- Denetimsiz öğrenme

- Pekiştirmeli (takviyeli) öğrenme

Denetimli öğrenme makine öğrenme modeli, hedef değerler ile sisteme giren veriler arasındaki ilişkiyi baz alan ve hedef değerlere benzer verilerin üretilmesini amaçlamaktadır. $\mathrm{Bu}$ sayede elde edilen model ile sisteme giren yeni veriler için en iyi sonucu verecektir. (Özkaya \& Seyfi, 2021)

Denetimsiz öğrenmede, hedef değer olmadan yalnızca giriş değerleri arasındaki ilişki belirlemeye çalışılır. Bu ilişki/ilişkiler yardımı ile birbirine benzer değerleri gruplandırılır yani küme haline getirir. Yeni gelen yeni girdi bilgisi önceden belirlenen kümelerden hangisi ile ilişikli ise o kümeye ait olacaktır.(Özkaya \& Seyfi, 2021)

Pekiştirmeli öğrenme, amaçlanan çıktı verisine ulaşabilmek için hedef veriler yerine, son olarak elde edilen çıkış verisinin, önceden verilen girişe göre olumlu veya olumsuz olarak değerlendiren bir ölçüt kullanılmaktadır. (Atalay \& Çelik, 2017)

Makine öğrenmesi ile ilgili birçok metot söz konusu. Çalışmamızda bu metotlar test edilecek ve en uygun algoritma seçimi yapılması hedeflenmektedir.

\subsubsection{Sistemin Genel Mantığı}

Tüm verilerin elde edilmesi, veri setleri haline dönüştürülmesi ve makine öğrenmesi metodu ile sulama sürelerine karar verme mekanizmasının merkezinde karar verici eleman olarak NodeMCU Wi-Fi özellikli gömülü sistem kullanılacaktır. Veriler elde edilmesi ve makine öğrenmesini karar merkezi olan NodeMCU, giriş verilerinde elde ettiği sonuca göre çıkışında bağlı bulunan ve MOSFET'lerden oluşacak olan sürücü devresi sayesinde selenoid valflerin kontörünü gerçekleştirecektir. Selenoid valfler elektriksel sinyallerle kontrol edilebilen valflerdir. $\mathrm{Bu}$ sayede merkezi işlemi biri tarafında belirlenen ve bitkiye özgü seçici sulama işlemi gerçekleştirilecektir.
Tüm bu sistemin elektrik enerjisi ile Fotovoltaik (güneş enerjisi) sistemi ile sağlanması planlanmaktadır. Hesaplanan enerji ihtiyacına göre 40W'lık bir Fotovoltaik panel ve $2 \mathrm{x} 12 \mathrm{~V}$ 7A'lik doğru akım aküleri ile sistemin enerji ihtiyacı karşılanabilecektir. Bu sayede sistemin çalışması için kurulu bir elektrik şebekesine ihtiyaç duyulmayacaktır.

\section{Araştırma Sonuçları ve Tartışma}

\subsection{Bulgular}

Yapılan çalışmada, sulama amacıyla kullanılacak olan suyun, bitkinin özellikleri ve çevresel sensör ağıdan elde edilen bilgilerin makine öğrenmesi yoluyla yorumlanarak ideal ölçüde kullanılması hedeflenmektedir. Ana amaç daha bitkiye özgü seçici sulama ile azami ölçüde verim elde etmekti. Bu doğrultuda çalışmanın ilk çıktısı olarak akıllı sulama sisteminin kontrol merkezi olan yapay zekâ destekli gömülü sistemin tasarımı gerçekleştirilmiştir. (Şekil 2 ve Şekil 3). Çalışmanın bu aşamasında laboratuvar ortamında gömülü sistemin çalışması test edilmiştir. Bu çalışmada ki bulgular; hali hazırda yapay zekâ desteği sisteme yüklenmemiştir. Sadece devrenin ve valflerin çalışma voltaj ve akımları test edilmiştir. (Şekil 10) Ayrıca her bir valfin ayrı ayrı kontrol edilebilirliği test edilmiştir. Devre elemanlarında özellikle sürücü MOSFET entegrelerinde ısınma tespit edilmemiştir.

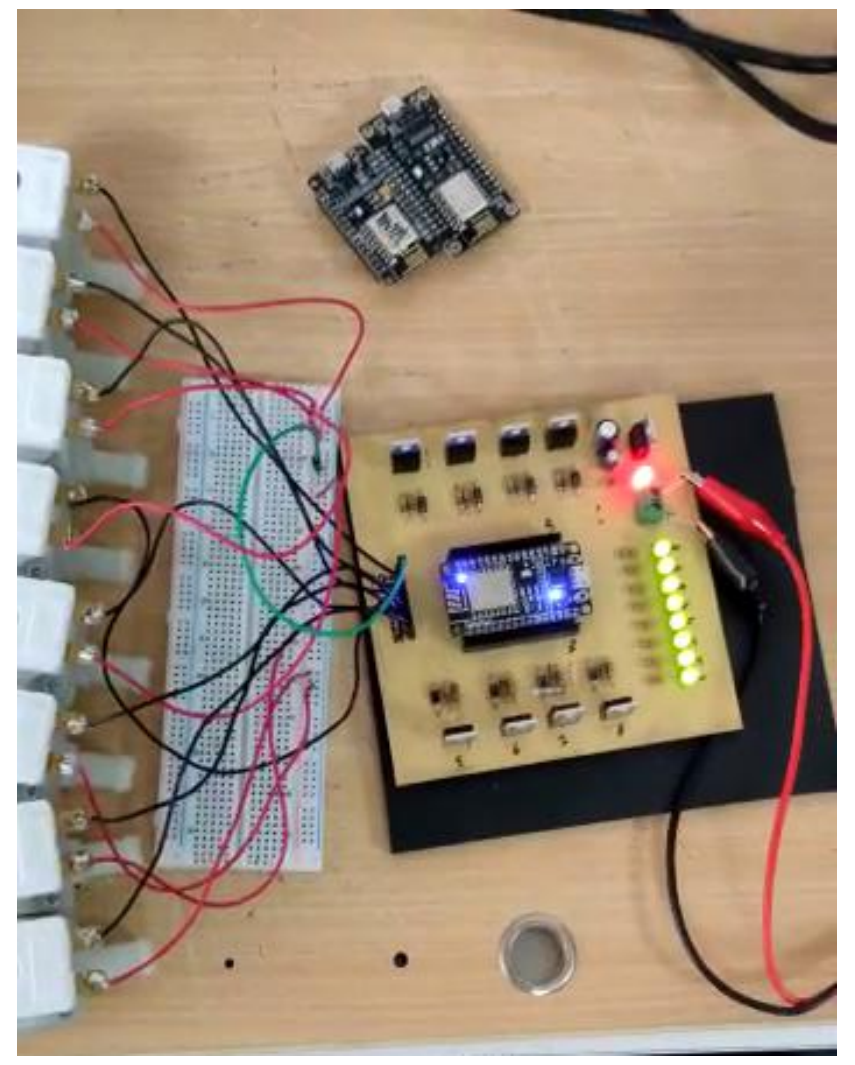

Şekil 10. Devre Testleri

Devrenin çalışma voltajı 12V DC gerilim olarak belirlenmiştir. $\mathrm{Bu}$ voltaj değerinde selenoid valfin çalışması ile ortaya çıkan Akım 0.97 A (970mA) olarak ölçülmüştür (Şekil11). Ancak yapılan testlerde 9V DC gerilime kadar selenoid valflerin çalıştığı gözlemlenmiştir. Bu sayede valflerin çektiği 
akım $0.56 \mathrm{~A}(560 \mathrm{~mA})$ kadar düşmüştür. Her iki durumda da sistemin için düşünülen $40 \mathrm{~W}^{\prime}$ lık Fotovoltaik güneş pilleri ve $2 \mathrm{x}$ 12V 7A' lik bataryaların yeterli olacağı düşünülmektedir.

Selenoid Valflerin içinde bulunan vanaların açılabilmesi ve sıvı akışına müsade etmesi için minimum $0.02 \mathrm{Mpa}$ (3 psi) bir akış debisine ihtiyaç olduğu tespit edilmiştir.

Yapılan testlerde selenoid valflerin açılma süresi: $\leq 0.15 \mathrm{sn}$ kapanma süresi: $\leq 0.3$ sn olarak gözlemlenmiştir.

$\mathrm{Bu}$ aşamadan sonra sistemin makine öğrenmesi çalışmalarına geçilmiş ve halen makine öğrenmesi üzerine çalışmalar devam etmektedir.

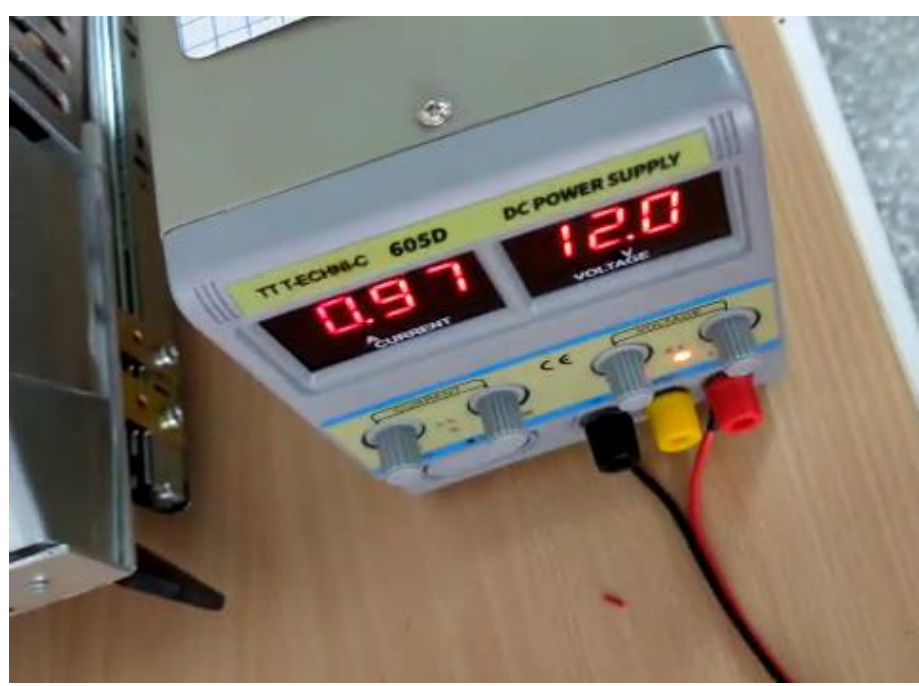

Şekil 11. Test Ölçümleri

\subsection{Tartışma}

Daha önce benzer alanda yapılan çalışmalarda küçük ölçekte zaten test edilmiş olan önerimiz, yalnızca gerektiğinde sulama yapmak yerine çevresel veriler analiz edebilen ve tarla/bahçe içinde yetiştirilmesi hedeflenen 8 farklı ürün için gereken doğru su miktarını anlayabilen algoritmaların kullanılması ve makine öğrenmesine dayalı bir sistem olmasıyla diğerler çalışmalardan ayrılmaktadır.

Daha önceki çalışmalar da sensörler ve kısıtlı algoritmalar ile oluşturulan sulama rejimlerinde $\% 25$ ve üstünde su tasarrufu sağladıkları tespit edilmiştir. Bu çalışmalarda tarla/bahçe sulama genel anlamda su tasarrufu üzerine gidilmiş, bitkilere özel bir sulama sürelerinin belirlenmesi için makine öğrenmesi ve yapay zekâ algoritmaları oluşturulmamıştır.

Çalışmamız her bir ürün için oluşturulacak sulama algoritması ile ürünün çeşidi ve topraktaki nem miktarına bağlı kalınarak bitkiye özgü sulama programı oluşturulacaktır. Bu sayede daha önceki çalışmalarda elde edilen su tasarrufunun üzerinde bir sonuç elde etmeyi hedeflemekteyiz.

Sonuçları iyileştirmek ve çözümün birden fazla ortamda çalışmasını garanti etmek için, daha güvenli bir sistem, makine izlemesi, uzaktan izleme ve yenilenebilir enerji yönetimi geliştirmeyi düşünmekteyiz.

\section{Sonuç}

Çalışmamız hali hazırda devam etmektedir. Bu nedenle sonuçları yerine çalışmamızın nihai hedeflerinden bahsetmek istiyorum.

Çalışmamızda yer alan proje tasarımı küçük ölçekli bahçe sulamaları için tasarlanmıştır. Kısa vade de bu alanda ihtiyaç duyulan seçici akıllı sulama sistemlerine cevap verebilecektir. Uzun vade de ise projemizin geliştirilerek daha büyük ölçekli tarım alanları ve meyve bahçelerinde kullanılması söz konusu olabilecektir.

Önerilen çalışmanın 4 temel amacı vardır ve bu amaçların her biri çalışmanın sonucu olarak yorumlanabilir. Bunlar;

1- Kurak veya yarı kurak bölgeler de verimli tarımın yapılabilmesi için bitkinin ihtiyaçlarına ve toprak nem özelliklerine uygun sulamanın yapılması,

2- Tarımda arazilerinde su israfının önüne geçilmesi,

3- Çalışmada planlanan 8 farklı bitki için (bu sayı verilerin toplanması için sınırlı tutulmuştur) sulama algoritması oluşturulması hedeflenmektedir. Her bir bitkinin su ihtiyacı birbirinden farklıdır ve bitkilerin sulama algoritmaları oluşturulması ve makine öğrenmesi ile bitkilerden elde edilecek verimin, asgari su düzeyi ile azami seviyeye çıkarılması hedeflenmektedir.

4- Sistemin için gerekli olan tüm enerji ihtiyacının yenilenebilir enerji kaynaklarında sağlanması ve karbon salınımı en aza indirmek ve çevre dostu bir sistem oluşturmaktır. Ayrıca yerleşim yerinde uzakta olan tarla/bahçeler içinde kesintisiz bir enerji kaynağ sağlanmış olacaktır.

\section{Teşekkür}

Çalışmanın hazırlanmasında sabırla büyük çaba sarf eden değerli hocam sayın Dr. Öğr. Üyesi Mahmut DURGUN'a, konu ile ilgili tecrübe ve bilgisini bizimle paylaşan değerli hocam sayın Dr. Öğr. Üyesi Levent GÖKREM'e, çalışmalarımın oluşturulması ve testlerinin gerçekleştirilmesi için ARGE Laboratuvarını kullanmam için izin veren Tokat Mesleki ve Teknik Anadolu Lisesi İdaresi ve çalışma arkadaşlarıma, çalışmalarım esnasında gösterdiği sabır ilgi ve alaka sebebiyle aileme şükranlarımı sunmayı bir borç bilirim.

\section{Kaynakça}

Atalay, M., \& Çelik, E. (2017). BüyükVeriAnalizinde Yapay Zekâ VeMakineÖğrenmesi Uygulamalari - Artificial Intelligence and Machine Learning Applications in Big Data Analysis. Mehmet Akif Ersoy Üniversitesi Sosyal Bilimler Enstitüsü Dergisi,

155-172. https://doi.org/10.20875/makusobed.309727

Baştuğ, R. (2014). Sebze üretiminde damla sulama yönetiminin temel ilkeleri. Derim, 31(1), 61. https://doi.org/10.16882/derim.2014.79864

Chang, Y.-C., Huang, T.-W., \& Huang, N.-F. (2019). A Machine Learning Based Smart Irrigation System with LoRa P2P Networks; A Machine Learning Based Smart Irrigation 
System with LoRa P2P Networks.

DHT11 Sicaklik ve Nem Sensörü. (n.d.). Retrieved September 18, 2021, from http://arduinoturkiye.com/dht11-sicaklik-venem-sensorunun-arduino-ile-kullanimi/,2021

Dorak, S., Aşik, B. B., \& Özsoy, G. (2019). Tarımda Su Kalitesi ve Su Kirliliğinin Önemi: Bursa Nilüfer Çayı Örneği. Bursa Uludă Üniversitesi Ziraat Fakültesi Dergisi, 33(1), 155-166.

Genel Kullanım Selenoid Valf. (n.d.). Retrieved September 18, 2021, from https://www.ayvaz.com/urunler/296-GenelKullanim-Selenoid-Valf.html

Jha, K., Doshi, A., Patel, P., \& Shah, M. (2019). A comprehensive review on automation in agriculture using artificial intelligence. In Artificial Intelligence in Agriculture (Vol. 2, pp. 1-12). KeAi Communications Co. https://doi.org/10.1016/j.aiia.2019.05.004

Kalkınma bakanlığı. (2018). Birinci Kalkinma Plani (2019-2023) Tarımda Toprak ve Suyun Sürdürülebilir Kullanımı. ÖzeIhtisasKomisyonu Raporu, 71-91.

Kapasitif Toprak Nem Sensörü - Higrometre. (n.d.). Retrieved September 18, 2021, from https://www.direnc.net/kapasitiftoprak-nem-sensoru, 2021

Kılavuz, E., \& Erdem, İ. (2019). Agriculture 4.0 Applications in the World and Transformation of Turkish Agriculture. EJournal of New World Sciences Academy, 14(4), 133-157. https://doi.org/10.12739/nwsa.2019.14.4.3c0189

NodeMcu -- An open-source firmware based on ESP8266 wifisoc. (n.d.). Retrieved September 18, 2021, from https://www.nodemcu.com/index_en.html\#fr_54745c8bd7 $75 \mathrm{ef} 4 \mathrm{~b} 99000011,2021$

Özel İhtisas Komisyonu Raporu. (2018). Su KaynaklarYönetimi VGüvenliği. 110.

Taştan, M. (2019). Nesnelerin İnterneti Tabanlı Akıllı Sulama ve Uzaktan İzleme Sistemi. European Journal of Science and Technology, 15, 229-236. https://doi.org/10.31590/ejosat.525149

Tatl, D., \& Amerika, K. (2000). Kentsel VeBireysel Su Tasarrufu.

Topuz, A., Tarihi, G., Erdoğan, B., Taşkaya Bülent, G., Üniversitesi, E., \& Bölümü, M. M. (2017). Araştırma Makalesi Fotovoltaik Etki ile Çalışan Güneş Enerjili Sulama Sisteminin Modellenmesi Modeling of the Solar Irrigation System Using Photovoltaic Effect. In Karaelmas Fen ve Müh. Derg (Vol. 7, Issue 2). http://fbd.beun.edu.tr 